\title{
Processo decisório no Poder Executivo: uma análise da Camex no presidencialismo de coalizão
}

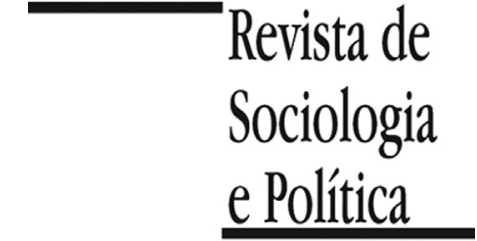

DOI $10.1590 / 1678987319276904$

\author{
Leonardo Gill Correia Santos' (iD \\ e Andrea Quirino Steiner" ic
}

RESUMO Introdução: Quem ganha mais em política de comércio exterior? Este estudo observa o processo decisório da Câmara de Comércio Exterior (Camex) no âmbito do presidencialismo de coalizão brasileiro. Ministros de Estado com preferências distintas são constrangidos a tomar decisões sobre propostas de políticas de comércio exterior. Nossa hipótese principal estabelece que, quanto maior a distância ideológica entre o partido de um ministro do partido do Presidente, menor será a chance de êxito desse ministro na Camex. Materiais e Métodos: A partir da análise de conteúdo das atas das reuniões do Conselho de Ministros da Camex entre 2001 e 2010, levantamos 292 propostas de defesa comercial e alterações tarifárias submetidas por ministros à Camex. Utilizamos, então, técnicas de regressão logística e de regressão logística para eventos raros (ReLogit) afim de verificar se a distância ideológica importa para a probabilidade de êxito dos ministros. Resultados: Apesar de algumas ressalvas metodológicas, nossos resultados permitem confirmar a hipótese do estudo, com impacto negativo e significativo da distância ideológica sobre o êxito dos ministros. Os modelos de regressão devem considerar oposições pontuais de membros da Camex sobre algumas propostas dos ministros no Conselho. Discussão: Verifica-se, portanto, que a Camex pode ser considerada uma instância de controle institucionalizado do presidente sobre o gabinete, para além dos controles já usualmente exercidos.

PALAVRAS-CHAVE: presidencialismo de coalizão; instituições políticas; Poder Executivo; Camex; comércio exterior

Recebido em 20 de Novembro de 2017. Revisado em 1 de Maio de 2018. Aceito em 1 de Julho de 2018.

\section{Introdução ${ }^{1}$}

\author{
1 Agradecemos aos \\ comentários e sugestões dos \\ pareceristas anônimos da \\ Revista de Sociologia e \\ Política. Agradecemos \\ também às contribuições de \\ Mariana Batista, Octávio \\ Amorim Neto e Marcelo \\ Medeiros, que se envolveram \\ de alguma forma com a \\ pesquisa que levou a este \\ estudo.
}

$\mathrm{Q}$ uem ganha mais em política de comércio exterior no Brasil? A Câmara de Comércio Exterior (Camex) é a principal entidade do Poder Executivo encarregada de tal missão. Sete ministros do governo devem rejeitar medidas, então submetidas ao órgão de decisão da Camex, o Conselho de Ministros. O interessante do processo decisório da instituição se deve ao fato de estar inserido no contexto do presidencialismo de coalizão no Brasil. A coalizão de governo é dividida entre partidos de origens diferentes, com eleitores e fontes de financiamento de campanha diversos. Neste sentido, é de se esperar que os partidos tenham interesses diferentes com relação às políticas de governo. As preferências podem muitas vezes ser conflitantes, o que pode afetar o processo decisório interno do Executivo. Não obstante, a Camex tem um processo de decisão institucionalizado, com um regimento interno definido e um grupo fixo de membros. Por isso é interessante observar como as dinâmicas que regem o presidencialismo de coalizão podem impactar as decisões da Camex. Qual partido tem mais vantagens na Câmara de Comércio Exterior? O presidente e seu partido aprovam mais medidas que os demais? A filiação partidária dos ministros importa para o êxito de suas propostas no Conselho de Ministros?

$\mathrm{O}$ argumento defendido aqui é que organizações institucionalizadas de tomada decisão dentro do Executivo, tais como a Camex, são instrumentos criados pela presidência para controlar partidos que compõem a coalizão de governo, mas com interesses distantes do partido do presidente. Tal raciocínio tem como base elementos teóricos sobre o Poder Executivo multipartidário, em 
2 Os autores utilizam as respostas de parlamentares brasileiros à Pesquisa Legislativa Brasileira (Power \& Zucco 2011a). que pelo menos dois partidos compõem o governo e devem tomar decisões conjuntamente (Müller, Bergman \& Strøm 2008), e sobre o presidencialismo, em que o chefe do Executivo é eleito de forma direta.

Para tanto, busca-se testar a hipótese de que quanto maior a distância ideológica entre o partido de um ministro em relação ao partido do presidente, menor será a probabilidade de êxito no Conselho de Ministros da Camex. Por um lado, estudos com base no Poder Executivo em sistemas parlamentaristas multipartidários entendem que a vantagem do partido formador do governo e o conflito entre partidos com preferências diferentes pode afetar as decisões do governo. Por outro, a literatura sobre presidencialismo de coalizão, em que o partido do presidente é inserido de maneira exógena no processo de formação do governo, observa os equilíbrios na relação de poder entre presidente e demais partidos da coalizão. Em ambos os sistemas, a tomada de decisão parece ser afetada pela distância ideológica entre os diferentes partidos. Cabe ressaltar, não obstante, que ministros podem usar o aparato burocrático e a capacidade técnica dos ministérios para favorecer suas propostas. Portanto, testa-se também se a capacidade técnica de a burocracia ministerial influenciar a probabilidade de êxito dos ministros na Camex.

Para testar as hipóteses são utilizados dados empíricos de diversas fontes. Primeiro, analisou-se a estrutura interna da Camex, a fim de entender a linha decisória da entidade, bem como qual deveria ser o enfoque analítico do estudo. Em seguida, foram analisadas as atas das reuniões do Conselho de Ministros da Camex, ocorridas entre 2001 e 2010, obtidas via Lei de Acesso à Informação (LAI - Lei 12.527/2011). As atas trazem as propostas feitas por ministros à Camex, e se eles conseguiram aprovar suas demandas, o que constitui a variável dependente do estudo: a probabilidade de êxito dos ministros no Conselho.

Com base nas propostas, utiliza-se os pontos ideais do partido dos ministros para verificar a distância com relação à posição do partido presidencial, aplicando dados de Zucco e Lauderdale $(2011)^{2}$ sobre pontos ideais dos partidos brasileiros. Para a capacidade técnica das burocracias ministeriais, foram utilizados os dados de Bersch, Praça e Taylor (2013) sobre capacidade das agências do Executivo. Como há um aparente viés a favor de um ministério específico, o MDIC, e a favor do êxito dos ministros nas iniciativas feitas à Camex, optou-se por uma regressão logística para eventos raros (ReLogit).

Além do viés a favor do MDIC, os resultados indicam que as distâncias ideológicas impactam negativamente a probabilidade de êxito dos ministros. Por sua vez, a capacidade técnica não obteve resultados significativos, nem ao interagir com a distância ideológica. Nesse sentido, a Camex parece constituir uma instituição de controle do presidente sobre os demais partidos, embora tal resultado precise ser avaliado com cautela.

A próxima seção descreve as funções da Camex e o processo decisório interno para delinear melhor o problema de pesquisa e o enfoque institucional. Em seguida, são apresentados alguns elementos teóricos com o objetivo de estabelecer algumas hipóteses. A quarta seção expõe como a coleta de dados foi realizada e como os dados foram manipulados. A quinta seção traz resultados empíricos e alguns pontos de discussão. Finalmente, apresenta-se as conclusões e futuras agendas de pesquisa.

\section{A Camex: instituição decisória do Poder Executivo}

Antes de aprofundar o debate teórico sobre o presidencialismo de coalizão e a coordenação entre atores no Poder Executivo, é necessário debruçar-se sobre a Camex e seu papel como entidade decisória. Na esteira da reformulação do Executivo no início da gestão de Fernando Henrique Cardoso (1995-2002), foi 
${ }^{3}$ Art. 7 da lei 9.649/1998.

${ }^{4}$ Lei 9.649/1998.

${ }^{5}$ É importante mencionar que esse Decreto foi amplamente alterado pelo Decreto 8.807/2016. Haverá uma breve análise sobre as mudanças na última parte do presente artigo.

${ }^{6}$ Embora seja de 2003, o Decreto 4.732/2003 retoma a estrutura estabelecida pelos decretos 3.756/2001 e 3.981/2001, que já estipulavam a emissão de resoluções. Embora o Conselho só tenha sido criado em 2003, as decisões analisadas anteriores já contavam com propostas de ministros feitas para a Camex. instaurado o Conselho de Governo, que tem como objetivo principal "assessorar o Presidente da República na formulação de diretrizes da ação governamental"'3. O Conselho é constituído essencialmente por câmaras, que têm como fim "formular políticas públicas setoriais, cujo escopo ultrapasse as competências de um único Ministério"4. A Camex foi criada pelo Decreto Presidencial 1.386/1995. Fernandes (2013) relata como a entidade passou por um processo de institucionalização, em que a burocracia interna do Ministério do Desenvolvimento, Indústria e Comércio Exterior (MDIC) foi favorecida na condução da política de comércio exterior, ao obter a Secretaria-Executiva da Camex (SE/Camex), órgão permanente da Camex, além da presidência da entidade, concedida ao ministro chefe do MDIC (com o Decreto 3.981/2001). Entretanto, o Decreto $4.732 / 2003^{5}$ é o que orienta o presente trabalho, pois define a estrutura interna da entidade, a composição da Camex e o processo decisório para os anos de interesse (2001-2010) ${ }^{6}$.

Nos anos de análise, a Camex é composta por três órgãos principais: 1) o Conselho de Ministros, órgão de decisão final composto por ministros de Estado do Executivo e presidido pelo MDIC; 2) o Comitê Executivo de Gestão (Gecex), órgão executivo encarregado de tomar decisões a serem apreciadas pelo Conselho e acompanhar a implementação das resoluções e demais decisões da entidade, composto pelo Presidente da Camex e de secretários executivos e membros do segundo escalão do Poder Executivo; e 3) a SE/Camex, órgão administrativo permanente, conduzido pelo Secretário Executivo, que acompanha as reuniões do Conselho, além de coordenar as atividades dos grupos de trabalhos interministeriais, responsáveis pela elaboração dos pareceres técnicos sobre as decisões.

O Conselho de Ministros é o órgão de interesse do presente estudo, tendo em vista que é o órgão decisório da entidade. Embora o Gecex também tenha prerrogativa de tomar decisões que poderão gerar efeitos, elas podem ser anuladas pelo Conselho. Portanto, prevalece a decisão deste sobre o Gecex. As decisões do Conselho são tomadas por maioria dos membros presentes (de acordo com o regimento interno válido no período de análise, estabelecido pelas resoluções 12/2001 e 11/2005), sendo necessária a participação de no mínimo quatro membros. As reuniões do Conselho, de acordo com o regimento interno, devem ocorrer uma vez por mês, mas, na prática, não há uma regularidade para o período analisado. Cabe ao Presidente do Conselho, no caso, o MDIC, convocar as reuniões.

Mais importante ainda, para este estudo, é a composição do Ministro do Desenvolvimento, Indústria e Comércio (MDIC); Ministro das Relações Exteriores (MRE); Ministro da Fazenda (MF); Ministro da Agricultura, Pecuária e Abastecimento (MAPA); Ministro do Planejamento, Orçamento e Gestão (MP); Ministro-Chefe da Casa Civil (CC); Ministro do Desenvolvimento Agrário (MDA - a partir de 2005). Podem participar das reuniões outros ministros ou membros do Executivo, desde que convidados pelo presidente do Conselho, no caso, o MDIC. Não fica claro, porém, se os convidados possuem poder de voto.

As decisões do Conselho são publicadas sob a forma de resoluções, mas não somente. Muitas vezes, não viram resoluções por não haver necessidade de publicação no Diário Oficial para gerarem efeitos: referem-se a posicionamentos em foros multilaterais de comércio. Além disso, propostas rejeitadas no Conselho também devem ser consideradas decisões, mesmo que não haja emissão de resolução. Por isso, houve um esforço de analisar as atas de reuniões, onde as medidas aprovadas e rejeitadas, bem como medidas que não necessitavam de resoluções, estavam amplamente detalhadas. Além disso, analisou-se os debates e posicionamentos dos ministros. 
Os ministros enviam as propostas à SE/Camex, que encaminha para um dos Grupos de Trabalho (GTs) especializados. Em seguida, a proposta é encaminhada ao Gecex ou ao Conselho. As propostas dirigidas ao Gecex são as que o Conselho já se pronunciou em casos semelhantes, estabelecendo uma dinâmica própria. O Conselho pode retomar ou rejeitar a medida. Embora haja mais membros do que no Conselho, as decisões no Gecex são tomadas por consenso. Sem consenso, a medida é encaminhada ao Conselho. Somente este, onde as medidas são tomadas por maioria, pode rejeitar uma medida. Vale mencionar que, nas atas as reuniões usadas para este trabalho, não há registo de atrito entre o Gecex e o Conselho. A linha decisória da Camex está esquematizada na Figura 1.

De acordo com a página oficial da entidade, são três os temas tratados pelos ministros: (1) financiamento de exportações; (2) negociações internacionais; (3) ajustes tarifários e (4) defesa comercial. O financiamento de exportações envolve programas de linha de crédito do Executivo para ajudar exportadores brasileiros a atingir mercados internacionais, envolvendo, em geral, o Banco do Brasil ou o Banco Nacional de Desenvolvimento Econômico e Social (BNDES). Isso explica, em parte, a presença de membros dessas entidades no Gecex.

Acerca das negociações internacionais, dois tipos de assuntos são tratados: (1) negociação de termos para novos acordos de comércio e (2) diretrizes para os acordos em que o Brasil já é signatário. Um exemplo do segundo ponto é a revisão periódica da Lista de Exceções à Tarifa Externa Comum (Letec) do Mercosul, cujos estudos são produzidos pelos grupos técnicos da Camex, pelo Gecex, pela Secretaria de Comércio Exterior do MDIC e por outros ministérios, a depender da agenda e dos produtos em questão. Os ministros definem, no Conselho, os termos gerais para orientar os estudos e, em seguida, aprovam as revisões da Letec.

É importante ressaltar sobre os três temas tratados no Conselho a diferença de natureza de cada um. As negociações internacionais e o financiamento de exportações são de cunho estratégico para o país, ainda mais quando se trata de

Figura 1 - Linha Decisória da Camex (2001-2010)

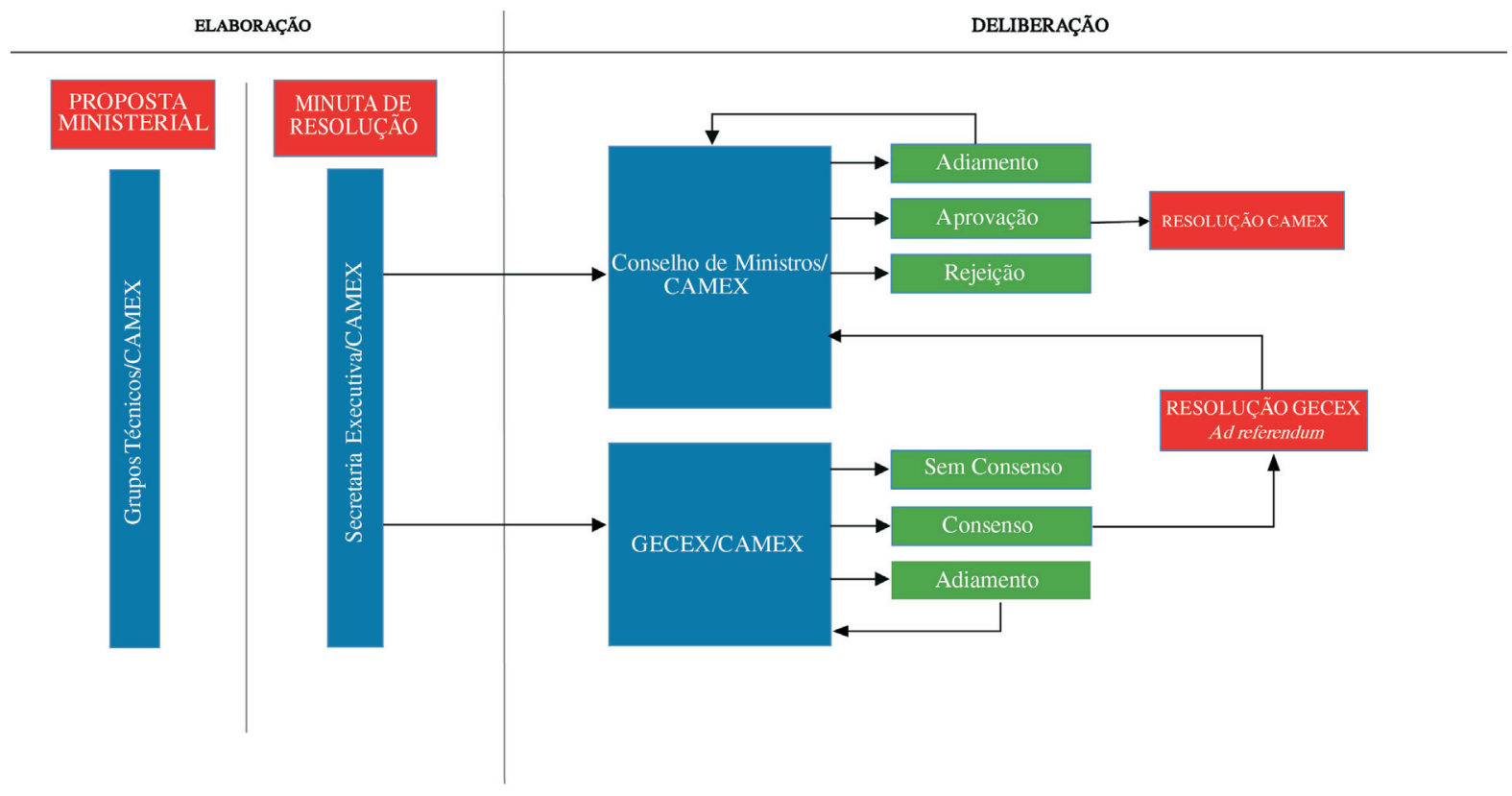

Fonte: Os autores. 
${ }^{7}$ Inciso II, art. 23, Lei 12.527/2011: "são consideradas imprescindíveis à segurança da sociedade ou do Estado e, portanto, passíveis de classificação as informações cuja divulgação ou acesso irrestrito possam:[...] prejudicar ou pôr em risco a condução de negociações ou as relações internacionais do País [...]”. acordos ainda não assinados. De fato, informações sobre essas medidas podem ser enquadradas como informações de acesso restrito, de acordo com o art. 23 da Lei 12.527/2011, conhecida como Lei de Acesso à Informação ${ }^{7}$. Por essa razão, nas atas de reuniões que compõem a parte empírica do presente estudo, foram autorizadas apenas as partes que diziam respeito a aspectos tarifários e de defesa comercial, bem como algumas sobre negociação internacional acerca da Letec.

Sobre as alterações tarifárias e de instauração de processos de defesa comercial, o art. $2^{\circ}$ do Decreto 4.732/2003 determina que é da Camex a competência sobre esses temas. Há dois tipos de medidas de defesa comercial: (1) medidas antidumping e (2) salvaguardas comerciais. O art. $2^{\circ}$ também estabelece que cabe à Camex fixar as alíquotas de importação e de exportação, entre outros tipos de alterações tarifárias.

A breve descrição da Camex serve a dois fins: (1) conhecer a estrutura do jogo que o problema de pesquisa se insere, o Conselho de Ministros; (2) esmiuçar os atores envolvidos. Porém, apesar do esforço de conhecer as regras formais aplicadas ao processo, surge um problema clássico do estudo de instituições: não são essas as únicas regras aplicadas. Há outras instituições que permeiam o Poder Executivo, além do Conselho de Ministros da Camex, que afetam as decisões da entidade. Outros estudos sobre o presidencialismo de coalizão indicam elementos teóricos de como algumas dessas organizações funcionam, como veremos a seguir.

\title{
III. Elementos Teóricos sobre o Processo Decisório em Executivo Multipartidário
}

\author{
III.1. Delegação no Executivo
}

O chefe do Poder Executivo, seja em sistemas parlamentares, seja em presidencialistas, tem recursos limitados para gerenciar a máquina administrativa do governo. Embora na teoria clássica da separação de poderes caiba ao Executivo a prerrogativa de executar medidas aprovadas pelo Legislativo, os parlamentares não podem tomar decisões sobre todas as medidas. Ou seja, o Legislativo delega ao chefe do Executivo discricionariedade decisória sobre certos assuntos. Por sua vez, o chefe do Executivo delega às agências, como os ministérios, poder de implementação sobre assuntos especiais. A relação de delegação do modelo principal-agente que se estabelece no Executivo não se faz sem custo, como destacam os estudos sobre o presidencialismo (Rudalevige 2002; Batista 2014) e o parlamentarismo (Strøm, Müller \& Bergman 2003; Martin \& Vanberg 2011; 2014).

Diversas variáveis afetam os custos de delegação. Em nosso caso, os custos estão atrelados à distância ideológica entre os membros do Executivo, ou entre a presidência e os membros de outros partidos alocados em ministérios.

Como se dá essa coordenação entre atores é o ponto central da próxima seção. O cerne do problema foi exemplificado da melhor maneira por Martin e Vanberg (2011, pp.3-4): "para governar com êxito, os parceiros da coalizão devem conseguir superar a tensão que existe entre acomodar mutuamente seus interesses coletivos e seus incentivos individuais na busca de objetivos políticos particulares" (tradução livre).

\section{III.2. Coordenação entre Membros do Executivo}

Estudos que pretendem analisar decisões e evidenciar quem ganha e quem perde nos jogos da política buscam antes de tudo definir as preferências dos atores. O que cada um quer? Como as preferências estão distribuídas no 
Executivo? Em primeiro lugar, isso depende da quantidade de atores envolvidos. Diferentemente dos sistemas eleitorais bipartidários, sistemas multipartidários tendem a criar governos de coalizão. Executivos fragmentados foram primeiro objeto de estudo em sistemas parlamentares, tendo em vista o caráter multipartidário de muitos desses sistemas. A fragmentação do Executivo em sistemas presidencialistas é menos evidente.

Em sistemas parlamentares multipartidários, quando nenhum partido obtém a maioria dos assentos no parlamento, os partidos devem formar coalizões majoritárias para compor o Executivo. Os estudos sobre processos decisórios demonstram que a governança nesses sistemas varia de acordo com o desenho institucional. Um modelo mais tradicional foi elaborado por Laver e Shepsle (1990; 1994; 1996), em que os membros do Executivo distribuem as pastas entre si - portfolio allocation - e possuem independência sobre as políticas implementadas por seu ministério, o que ficou conhecido como o modelo de autonomia ministerial. Como o ministro tem autonomia decisória sobre sua pasta, as preferências do partido do ministro deveriam prevalecer. Porém, se os temas envolverem mais de um ministério, como ficaria a decisão? Decisões colegiadas entre diversos atores levaram Martin e Vanberg $(2011 ; 2013 ; 2014)$ a criar um modelo alternativo, o acordo da coalizão, em que as preferências do Executivo se pareceriam mais com uma combinação dos interesses dos partidos que constituem o gabinete.

Em sistemas presidencialistas multipartidários, a situação se altera. Há uma tendência a analisar executivos presidencialistas sob a perspectiva americana, em que apenas um partido constitui o governo. Essa perspectiva mostra-se insuficiente para o presidencialismo com coalizões (Cheibub 2007), como ocorre em alguns países na América Latina. A diferença sensível dos sistemas parlamentares se dá pelo fato de que, em presidencialismos, um dos membros do Executivo, o presidente, se insere no governo de forma exógena ao processo de composição e de negociação dos partidos da base governamental (Batista 2014). Ao mesmo tempo, o partido que ocupa a presidência é responsável pela formação, sendo o partido formador (Rubinstein 1982; Cheibub, Przeworski \& Saiegh 2002). Em sistemas parlamentares, tal partido é o que tem menos custo para iniciar a formação do governo (Riker 1962). No presidencialismo, quem tem menos custo é o partido que obrigatoriamente estará no governo, o presidencial, eleito pelo sistema majoritário em pleito nacional (Quadro 1).

Por que o partido presidencial forma coalizões no Executivo? Esse é um dos temas de um importante debate na Ciência Política no Brasil (Batista 2014). Para aprovar sua agenda de governo, o presidente precisa aprovar medidas, principalmente questões orçamentárias, no Legislativo. Para garantir as maiorias necessárias nas câmaras, o partido presidencial tem a seu alcance dois instrumentos: cargos e emendas orçamentárias (Amorim Neto 2000; 2002; 2006; Figueiredo \& Limongi 2001; 2008; Batista 2014). Esse é o motor que gera a formação das coalizões no presidencialismo brasileiro, e certa preponderância é dada ao presidente e seu partido, em função dos recursos à sua disposição para administrar a coalizão e a estabilidade do governo. O Quadro 1 indica o tamanho e a duração das coalizões de cada mandato presidencial entre 1990 e 2014.

As coalizões governamentais no Brasil se tornaram cada vez mais complexas à medida que o número de partidos membros do Executivo foi aumentando. Mais do que o número de partidos, aumentou também a pluralidade de interesses de cada membro. Utilizando dados de Zucco e Lauderdale (2011) de pontos ideais dos partidos brasileiros no Congresso, o Gráfico 1 indica como o Executivo tornou-se cada vez mais plural. 
Quadro 1 - Coalizões Governamentais no Brasil (1990-2014)

\begin{tabular}{|c|c|c|c|c|c|}
\hline Presidente & Partido & Coalizões & Partidos no Gabinete & $\mathbf{N}$ & Período \\
\hline \multirow{4}{*}{$\begin{array}{l}\text { Fernando } \\
\text { Collor de } \\
\text { Mello }\end{array}$} & \multirow[t]{4}{*}{ PRN } & Collor 1 & PRN-PFL & 2 & 1990 \\
\hline & & Collor 2 & PRN-PFL-PDS & 3 & 1990-1991 \\
\hline & & Collor 3 & PRN-PFL-PDS & 3 & 1991-1992 \\
\hline & & Collor 4 & PRN-PFL-PDS-PTB-PL & 5 & 1992 \\
\hline \multirow[t]{3}{*}{ Itamar Franco } & \multirow[t]{3}{*}{ Sem filiação } & Itamar 1 & PFL-PTB-PMDB-PSDB-PSB & 5 & 1992-1993 \\
\hline & & Itamar 2 & PFL-PTB-PMDB-PSDB-PP & 5 & 1993-1994 \\
\hline & & Itamar 3 & PFL-PMDB-PSDB-PP & 4 & 1994 \\
\hline \multirow{4}{*}{$\begin{array}{l}\text { Fernando } \\
\text { Henrique } \\
\text { Cardoso }\end{array}$} & \multirow[t]{4}{*}{ PSDB } & FHC I 1 & PSDB-PFL-PMDB-PTB & 4 & 1995-1996 \\
\hline & & FHC I 2 & PSDB-PFL-PMDB-PTB-PPB & 5 & 1996-1998 \\
\hline & & FHC II 1 & PSDB-PFL-PMDB-PPB & 4 & 1999-2002 \\
\hline & & FHC II 2 & PMDB-PSDB-PPB & 3 & 2002 \\
\hline \multirow{7}{*}{$\begin{array}{l}\text { Luiz Inácio } \\
\text { Lula da Silva }\end{array}$} & \multirow[t]{7}{*}{ PT } & Lula I 1 & PT-PL-PCdoB-PSB-PTB-PDT-PPS-PV & 8 & 2003-2004 \\
\hline & & Lula I 2 & PT-PL-PCdoB-PSB-PTB-PPS-PV-PMDB & 8 & 2004-2005 \\
\hline & & Lula I 3 & PT-PL-PCdoB-PSB-PTB-PV-PMDB & 7 & 2005 \\
\hline & & Lula I 4 & PT-PL-PCdoB-PSB-PTB-PMDB & 6 & 2005 \\
\hline & & Lula I 5 & PT-PL-PCdoB-PSB-PTB-PP-PMDB & 7 & 2005-2007 \\
\hline & & Lula II 1 & PT-PCdoB-PR-PMDB-PP-PSB-PTB & 7 & 2007 \\
\hline & & Lula II 2 & PT-PCdoB-PDT-PMDB-PP-PR-PSB-PTB & 8 & $2007-2010$ \\
\hline \multirow{2}{*}{$\begin{array}{l}\text { Dilma Vana } \\
\text { Rousseff }\end{array}$} & \multirow[t]{2}{*}{ PT } & Dilma I 1 & PT-PCdoB-PDT-PMDB-PP-PR-PSB & 7 & 2011-2012 \\
\hline & & Dilma I 2 & PT-PCdoB-PDT-PMDB-PP-PR-PSB-PRB & 8 & $2012-2014$ \\
\hline
\end{tabular}

Fonte: Os autores, a partir de Figueiredo (2007) e Batista (2014).

As distâncias ideológicas (DI) são obtidas pela distância euclidiana entre a posição de um partido e o partido do presidente. O lado esquerdo do Gráfico 1 corresponde ao das barras, que indica a soma das distâncias de cada coalizão, enquanto o lado direito, da linha preta, se refere à média das distâncias de cada

Gráfico 1 - Dispersão ideológica das coalizões presidenciais no Brasil (1990-2010)

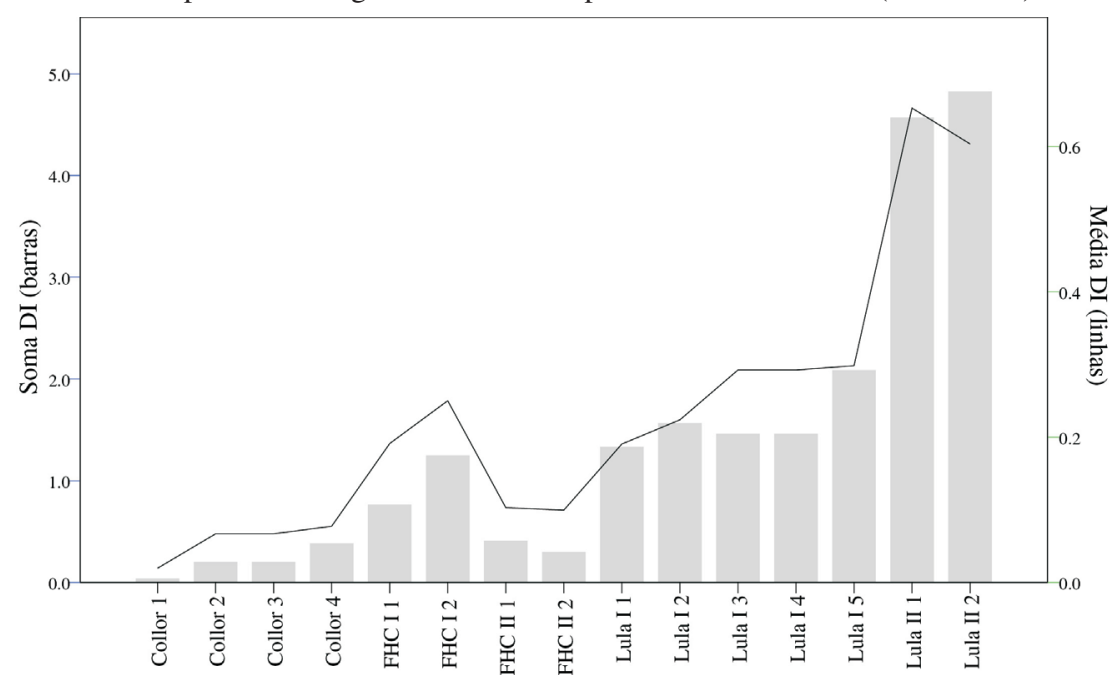

Fonte: Os autores, a partir de Figueiredo (2007), Batista (2014) e Zucco e Lauderdale (2011). 
coalizão ${ }^{8}$. O Gráfico 1 qualifica ainda mais a complexidade da coalizão (Batista 2014). Como essa complexidade afetaria a Camex?

\section{III.3. Coordenação entre membros do Conselho da Camex}

8 Não há dados para o Partido Verde (PV) para a legislatura do primeiro mandato de Lula (2003-2006), embora o partido fizesse parte da coalizão.
De acordo com o levantamento realizado, o processo decisório na Camex pode refletir mais os interesses de um ministro de um partido da coalizão, do membro médio da coalizão ou do partido do presidente. Porém, há indícios de que o presidencialismo tenda a favorecer o partido do presidente, já que (1) é o partido formador; (2) a presidência delega autoridade para as agências governamentais, como a Camex; (3) é de interesse do presidente institucionalizar o processo decisório, para monitorar os membros da coalizão (Inácio 2006; Lameirão 2011; Batista 2014). Ou seja, a tendência é que a Camex reflita mais os interesses do partido do presidente. Nesse sentido, a primeira hipótese levantada é a seguinte:

H1: Quanto maior a distância ideológica entre o partido de um ministro do partido do presidente, menor será o êxito desse ministro no Conselho de Ministros da Camex.

\section{III.4. Capacidade Técnica Ministerial}

Até então, somente nos centramos em aspectos institucionais ligados à coalizão. Os ministros sabem que o presidente tentará utilizar sua força para mobilizar a maioria dos ministros em favor de medidas de seu interesse. Lembramos que, no modelo de Laver e Shepsle (1990) de autonomia ministerial, os ministros estão à frente de uma burocracia especializada em temas diversos. Há uma enorme assimetria de informações entre ministérios e a presidência, bem como entre os próprios ministérios, que varia de acordo com a capacidade dos técnicos ministeriais. Diante desse quadro, nada impede que ministros façam usos estratégicos das burocracias para defender seus interesses na Camex. Bersch, Praça e Taylor (2016) defendem a integração de variáveis sobre qualidade burocrática em estudos sobre o presidencialismo de coalizão. Imaginando que a capacidade técnica de membros ministeriais possa influir no êxito dos ministros na Camex, a segunda hipótese afirma que:

H2: Quanto maior a capacidade de um ministério, maior o êxito do ministro no Conselho de Ministros da Camex.

\section{Desenho de Pesquisa}

IV.1. Variável dependente: êxito dos ministros na Camex

Para observar o processo decisório interno da Camex, é necessário destrinchar as reuniões do Conselho de Ministros. A LAI (Lei 12.527/2011) permitiu acessar as atas das reuniões do Conselho entre 2001 e 2010 para temas de defesa comercial e alterações tarifárias. É importante destacar que "financiamento internacional" e "negociações internacionais" não foram disponibilizados por sigilo estratégico9. Ademais, apesar da Camex existir desde 1995, ela só passou a emitir resoluções a partir de 2001. Das 78 reuniões da Camex realizadas no período, as atas continham trechos de 59 delas, ou $76 \%$ do total. A análise de conteúdo permitiu compreender melhor como elas se organizaram. Por reunião, as atas expunham o seu número, a data, a lista de presença (incompleta) e os temas tratados. Estes eram tratados em uma estrutura que se repetia quase sempre na seguinte sequência: (1) a proposta a ser votada, por vezes acompanhada de alguma justificativa; (2) a origem da demanda (ministro, ministério, algum órgão da Camex ou eventualmente algum grupo privado); (3) a decisão 
do grupo, que podia ser uma aprovação total da medida, uma aprovação parcial com ao menos uma alteração, o adiamento para uma futura reunião ou a rejeição.

Considerando cada proposta como um caso, verificou-se qual foi o tratamento dado pelos ministros. No caso de aprovação total, considerou-se o êxito da demanda do ministro. Convencionou-se dar o mesmo tratamento para uma aprovação parcial, desde que a medida não fosse completamente modificada. Quando a decisão foi adiada, só foi considerado como exitosa a proposta retomada e aprovada em reunião futura, o que implicou, muitas vezes, realizar uma busca pela resolução no site da Camex (2017). É considerado como fracasso a rejeição implícita ou explícita da medida: explícita, quando a proposta é sumariamente recusada pelos ministros; implícita, quando a proposta é adiada até não voltar à pauta da reunião.

Para o tratamento estatístico, criou-se uma variável binária, em que 0 corresponde ao fracasso da medida e 1 ao êxito.

\section{IV.2. Variáveis independentes: distância ideológica e capacidade ministerial}

Para cada caso, levantou-se a origem da proposta submetida, que podia ser: 1) um ministro específico; 2) um órgão ministerial (secretaria ou departamento); 3) um grupo de interesse.

No primeiro caso, o tratamento é mais simples. Atribui-se a origem ao ministro do momento. No segundo caso, considerou-se o ministro que ocupou um cargo de chefia na pasta, atribuindo-se a proposta ao ministro-chefe na data da reunião. Quando a proposta é feita por algum grupo técnico da Camex ou da SE/Camex, atribui-se ao MDIC a origem da proposta. No comando da SE/Camex está o Secretário-Executivo da entidade, que é também quem coordena os grupos técnicos da Camex. De acordo com o Decreto 4.732/2003, quem indica o Secretário-Executivo é o presidente do Conselho de Ministros da Camex. Nos anos avaliados, o presidente do Conselho é o MDIC. Há, portanto, uma relação principal-agente entre o SE/Camex e o MDIC. Por essa razão, estabeleceu-se que as propostas da SE/Camex e dos grupos técnicos são de origem do MDIC. Finalmente, para o caso de propostas feitas por grupos de interesse, observou-se que os ministros não votavam a demanda do grupo em questão, mas o parecer do MDIC favorável ou desfavorável à proposta. Nesse sentido, convencionou-se atribuir essas demandas particulares ao MDIC.

O uso da distância ideológica como forma de medir a diferença entre as preferências dos partidos na coalizão não é um recurso novo. Batista (2013; 2014) o utilizou para medir a probabilidade de centralização das propostas legislativas na presidência. Com base nesse estudo, para estabelecer a distância ideológica, foram utilizados os dados de Zucco e Lauderdale (2011) sobre pontos ideais dos partidos para cada mandato ${ }^{10}$. A escala varia entre $1 \mathrm{e}-1$, em que a proximidade com "1" indica mais inclinação à direita. Os autores estabelecem pontos ideais para cada partido a partir de surveys realizados com parlamentares, no âmbito da Pesquisa Legislativa Brasileira elaborada por Power e Zucco (2011a) ${ }^{11}$. O Quadro 2 indica a composição das coalizões do Executivo para os anos das atas das reuniões para as quais há informações. $\mathrm{O}$ Gráfico 2 mostra o grau de dispersão ideológica entre os partidos em cada coalizão $^{12,13}$. Utilizando os dados e de acordo com a primeira hipótese, tomou-se o partido presidencial como ponto de referência. Em seguida, aplicou-se a fórmula de distância euclidiana para estabelecer a distância ideológica $D I$ entre os partidos:

$$
D I=\sqrt{\left(P_{P}-P_{P i}\right)^{2}}
$$


Quadro 2 - Composição das coalizões presidenciais no Brasil (1999-2010)

\begin{tabular}{lcccc}
\hline Presidente & Partido do Presidente & Coalizão & Partidos da Coalizão & Período \\
\hline Fernando Henrique & \multirow{2}{*}{ PSDB } & FHC II 1 & PSDB-PMDB-PFL-PPB & $1999-2002$ \\
Cardoso & & PSDB-PMDB-PPB & 2002 \\
Luiz Inácio Lula da & PT & Lula I 1 & PT-PL-PCdoB-PSB-PTB-PDT-PPS-PV & $2003-2004$ \\
Silva & & Lula I 2 & PT-PL-PCdoB-PSB-PTB-PPS-PV-PMDB & $2004-2005$ \\
& Lula I 3 & PT-PL-PCdoB-PSB-PTB-PV-PMDB & 2005 \\
& Lula I 4 & PT-PL-PCdoB-PSB-PTB-PMDB & 2005 \\
& Lula I 5 & PT-PL-PCdoB-PSB-PTB-PP-PMDB & $2005-2007$ \\
& Lula II 1 & PT-PCdoB-PL-PMDB-PP-PSB-PTB & 2007 \\
& Lula II 2 & PT-PCdoB-PDT-PMDB-PP-PR-PSB-PTB & $2007-2010$ \\
\hline
\end{tabular}

Fonte: Os autores, a partir de Batista (2014) e Figueiredo (2007).

não há dados sobre sua posição ideológica. $\mathrm{O}$ partido abandonou a coalizão em 2005, por isso não havendo diferença na, Figura 2, entre as coalizões Lula I 3 e 4.

${ }^{13}$ Nas 3 primeiras coalizões do primeiro mandato de Lula, PSB, PDT e PPS estão bastante próximos, assim como PL e PTB nas 5 coalizões desse mandato, causando uma sobreposição à esquerda e à direita.

\footnotetext{
14 Para justificar o uso no contexto do presente trabalho, foi feito um teste de robustez da mesma regressão da Tabela 2 , exclusivamente com as propostas de ministros filiados a partidos. Os resultados, disponibilizados na Tabela A1 (Apêndice), continuam significantes e os coeficientes permanecem no mesmo patamar.
}

Gráfico 2 - Pontos ideais dos partidos na coalizão (1999-2010)

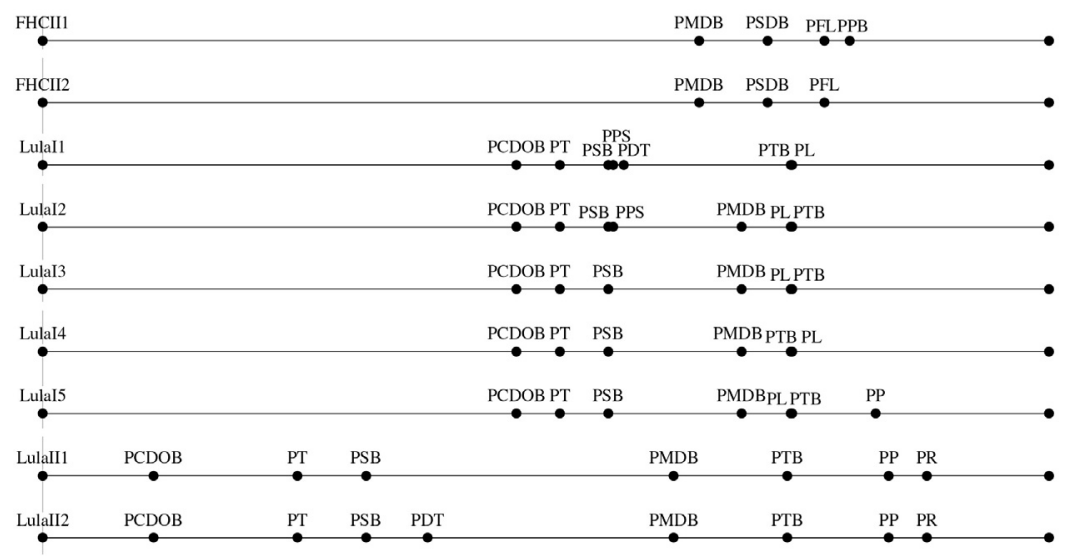

Fonte: Os autores, a partir de Zucco e Lauderdale (2011).

em que $P_{P}$ é a posição ideológica do partido do presidente na coalizão e $P_{P i}$ é a posição ideológica de um partido $i$ na mesma coalizão. Assim, para cada ministro proponente, verifica-se qual o seu partido e atribui-se a DI correspondente.

A distância euclidiana nada mais é do que o intervalo entre pontos ideais, independente da posição desses partidos. Quanto aos ministros sem filiação partidária é necessário destacar que se optou por lhes atribuir o mesmo partido do presidente ${ }^{14}$. Batista (2013) fez algo parecido, embora haja mais propostas com ministros filiados. Neste estudo, trata-se de uma escolha metodológica que pode comprometer os resultados, tendo em vista o grande número de propostas de ministros sem filiação partidária.

Para a capacidade técnica, Bersch, Praça e Taylor (2016) criaram um índice de capacidade técnica das agências governamentais, disponibilizado no repositório de dados do The State Capacity Project (idem), uma medida do esprits de corps das agências. $\mathrm{O}$ índice combina proporção dos funcionários de carreira (concursados), longevidade na carreira, requisições de experts de outras agências governamentais e salário médio. Ou seja, é uma medida meritocrática das agências: quanto maior o índice, maior a capacidade dos técnicos, numa escala de -1 a 1 . Nesse sentido, para cada ministro ou ministério que realiza a proposta, atribui-se a ele a capacidade correspondente à sua agência. 
IV.3. Variáveis de controle

IV.4. Regressão Logística

\section{Resultados e discussão}

A Tabela 1 indica o número de propostas realizadas por ministérios.

Ao total, foram levantados 292 casos. Há claramente um viés a favor do MDIC na iniciativa de propostas, o que talvez se deva às escolhas metodológicas. Vale mencionar também que muitas das iniciativas do MDIC são revisões obrigatórias da Letec e pareceres de demandas de grupos de interesse. Também 
Tabela 1 - Número de Propostas por Ministério (2001-2010)

\begin{tabular}{lc}
\hline Ministério & Iniciativas \\
\hline MDIC & 232 \\
MRE & 2 \\
MF & 10 \\
MAPA & 28 \\
MP & 0 \\
Casa Civil & 0 \\
MDA & 7 \\
MD & 3 \\
MJ & 3 \\
MME & 1 \\
MPA & 1 \\
MS & 5 \\
Total & 292 \\
\hline
\end{tabular}

Fonte: Os autores. O glossário de siglas está no apêndice do artigo.

se destacam as propostas de outros ministérios, além dos membros permanentes do Conselho da Camex: Ministério da Defesa (MD), Ministério da Justiça (MJ) Ministério de Minas e Energia (MME), Ministério da Pesca e Aquicultura (MPA) e Ministério da Saúde (MS). Os ministros participam das reuniões, mas não fica evidente se fazem parte do processo decisório. Outro ponto que vale ressaltar é a escassa participação do MRE, MP e da Casa Civil. Se por um lado as participações desses ministérios possam estar atreladas aos assuntos que a LAI não permite acesso, por outro, os ministros dessas pastas levantam diversas oposições às propostas de outros ministros.

O Gráfico 3 confirma o viés a favor do êxito e, em particular, ao MDIC (96,98\% de êxito). Sobre o total de demandas de cada ministério, o êxito se reparte de maneira desigual, em que certos ministérios ganham mais do que outros de forma desproporcional. Os ministérios que mais perdem são MAPA (êxito em 46,42\% das propostas), MDA (57,14\%), MJ e MD (ambos com $33,3 \%$ ). Curiosamente, ministérios ligados à agricultura são menos privilegiados que os demais.

Porém, analisar êxitos e fracassos dos ministérios sem propor alguma análise mais estrutural não permite confirmar as hipóteses de estudo. Das 292 propostas, há 29 fracassos e 263 êxitos, isto é, em torno de $10 \%$ de fracassos, o que nos permite qualificar um viés a favor do êxito na Camex. A variável da distância ideológica teve uma média de 0,08, com um desvio padrão de 0,23, com um valor mínimo de 0 e máximo de 0,75 .

Há um problema que pode afetar o estudo estatístico proposto: há pouquíssima variação de distância ideológica. Em alguns anos, como no primeiro mandato de Lula, não há proposta de ministros de outro partido ou sem filiação partidária. Entre os que fizeram propostas na Camex, os únicos ministérios que estiveram com partidos distintos que o do presidente estão MAPA, MD, MS e MME, todos com o PMDB em algum momento ${ }^{15}$. Ou seja, a variável independente de distância ideológica tem pequena variabilidade, o que compromete um pouco o achado empírico.

A variável da capacidade tem uma variação maior, com um valor mínimo de $-1,03$ e máximo de 1,44; a média ficou em -0,06 e o desvio padrão em 0,43. A
15 O MAPA esteve com o PPB no segundo mandato de FHC. 
Gráfico 3 - Êxitos das propostas à Camex, por Ministério (2001-2010)

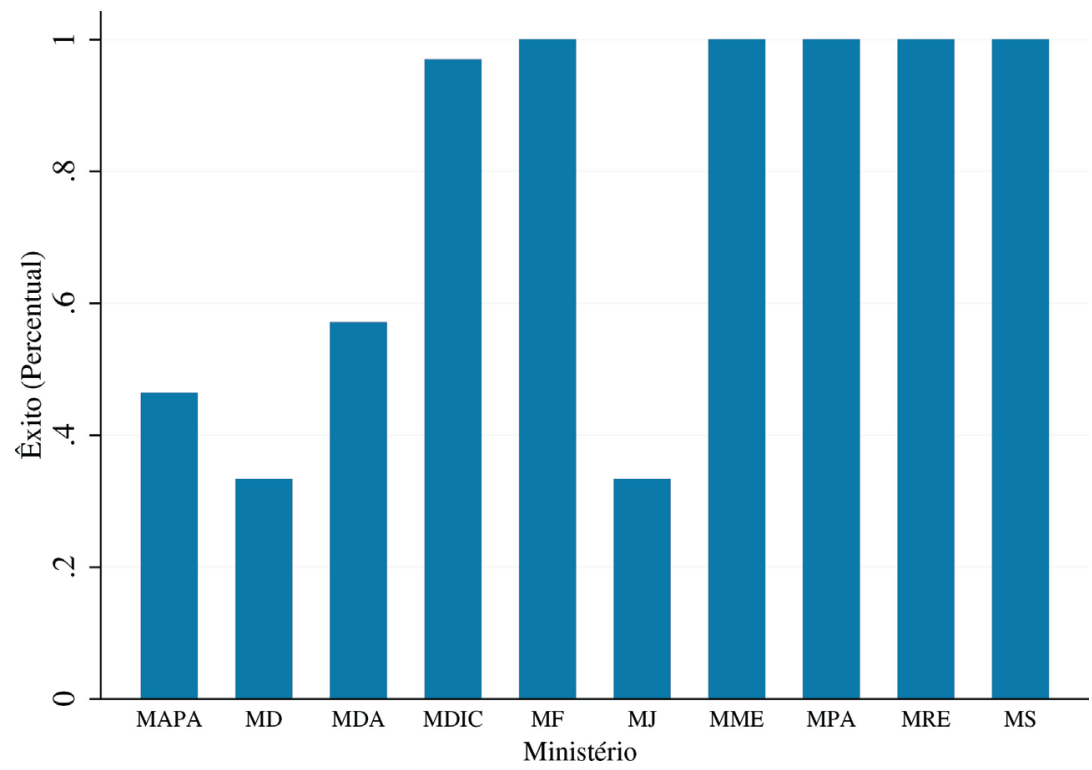

Fonte: Os autores. O glossário de siglas está no apêndice do artigo. $\mathrm{N}=292$.

variável de oposição teve uma média de 0,089 , o que corresponde a um total de 26 manifestações de oposição (Tabela 2).

A Tabela 2 mostra a regressão logística convencional. O Modelo 1 corresponde a um teste de robustez do Modelo 2, em que se verifica o impacto das variáveis independentes sem as variáveis de controle, que confirma os achados empíricos. De fato, o Modelo 2 confirma a Hipótese 1, sobre distância ideológica, demonstrando resultado negativo significativo, conforme esperado. A variável de capacidade não obteve significância. Um achado interessante se refere ao resultado da variável de oposição que, como esperado, obteve resultado negativo e significante. No Modelo 3, testou-se uma variável de interação entre distância ideológica e capacidade técnica, que não trouxe achados importantes.

Em todos os modelos estão dispostos os coeficientes de regressão e os odd ratios (OD) (razões de chance), que indicam as probabilidades de maneira mais clara: quando os ODs são inferiores a 1, a relação é negativa, e um aumento de uma unidade na variável independente diminui a probabilidade de êxito em $\mathrm{p}=1-\beta$, isto é, $99,9 \%$ no Modelo 2 para a distância ideológica $(\mathrm{p}=1-0,008)$.

A Tabela 3, da regressão logística para eventos raros, traz resultados semelhantes aos da Tabela 2, o que atenua os problemas estatísticos do estudo. O Modelo 2 confirma a Hipótese 1 (impacto negativo e significância). O mesmo ocorre com a variável de oposição. A variável capacidade não obteve resultado esperado (sinal negativo) nem obteve significância, não confirmando Hipótese 2.

A Gráfico 4 foi obtido em função da regressão logística convencional (Tabela 2). Há de fato uma relação negativa entre a distância ideológica e a probabilidade de êxito dos ministros. Por outro lado, o intervalo de confiança, que se expande à medida que a distância ideológica aumenta, confirma o viés a favor do êxito e do MDIC: há menos casos com fracassos de iniciativas de ministros mais distantes ideologicamente do presidente do que casos de êxito de propostas de ministros mais próximos, ou até do mesmo partido. 
Tabela 2 - Regressão logística (VD = Número de Êxito dos Ministros)

\begin{tabular}{|c|c|c|c|c|c|c|}
\hline \multirow[b]{2}{*}{ Variáveis } & \multicolumn{2}{|c|}{ Modelo 1} & \multicolumn{2}{|c|}{ Modelo 2} & \multicolumn{2}{|c|}{ Modelo 3} \\
\hline & Coef & OR & Coef & OR & Coef & OR \\
\hline \multirow[t]{2}{*}{ Constante } & $3,704 * * *$ & $40,605 * * *$ & $2,840 * * *$ & $17.122 * * *$ & $2,833 * * *$ & $16,991 * * *$ \\
\hline & $(0,427)$ & $(17,333)$ & $(1,054)$ & (18.045) & $(1,049)$ & $(17,829)$ \\
\hline \multirow{2}{*}{$\begin{array}{l}\text { Distância } \\
\text { Ideológica }\end{array}$} & $-4,546 * * *$ & $0,011 * * *$ & $-4,806 * * *$ & $0,008 * * *$ & $-4,561 * * *$ & $0,010 * * *$ \\
\hline & $(0,933)$ & $(0,009)$ & $(1,001)$ & $(0,008)$ & $(1,177)$ & $(0,012)$ \\
\hline \multirow[t]{2}{*}{ Capacidade } & $-0,093$ & 0,911 & $-0,070$ & 0,932 & 1,609 & 5,000 \\
\hline & $(0,543)$ & $(0,494)$ & $(0,555)$ & $(0,517)$ & $(1,222)$ & $(6,111)$ \\
\hline \multirow[t]{2}{*}{ Oposição } & $-3,236 * * *$ & $0,039 * * *$ & $-3,241 * * *$ & $0,039 * * *$ & $-3,085 * * *$ & $0,046 * * *$ \\
\hline & $(0,595)$ & $(0,023)$ & $(0,627)$ & $(0,024)$ & $(0,640)$ & $(0,029)$ \\
\hline \multirow{3}{*}{$\begin{array}{l}\text { DI x } \\
\text { Capacidade }\end{array}$} & & & & & $-3,170$ & 0,042 \\
\hline & & & & & & \\
\hline & & & & & $(1,967)$ & $(0,083)$ \\
\hline \multirow[t]{2}{*}{ Presidente } & & & 0,951 & 2,587 & 1,224 & 3,401 \\
\hline & & & $(1,150)$ & $(2,975)$ & $(1,150)$ & $(3,913)$ \\
\hline \multirow[t]{2}{*}{ Ano 1} & & & $-0,380$ & 0,685 & $-0,182$ & 0,834 \\
\hline & & & $(0,642)$ & $(0,439)$ & $(0,672)$ & $(0,560)$ \\
\hline \multirow[t]{2}{*}{ Ano 4} & & & 0,655 & 1,924 & 0,646 & 1,908 \\
\hline & & & $(0,716)$ & $(1,379)$ & $(0,719)$ & $(1,373)$ \\
\hline Log Likelihood & \multicolumn{2}{|c|}{$-62,404994$} & \multicolumn{2}{|c|}{$-61,461721$} & \multicolumn{2}{|c|}{$-60,00956$} \\
\hline LR chi $^{2}$ & \multicolumn{2}{|c|}{64,16} & \multicolumn{2}{|c|}{66,04} & \multicolumn{2}{|c|}{68,95} \\
\hline Prob $>\mathrm{chi}^{2}$ & \multicolumn{2}{|c|}{0,000} & \multicolumn{2}{|c|}{0,000} & \multicolumn{2}{|c|}{0,000} \\
\hline Pseudo $\mathrm{R}^{2}$ & \multicolumn{2}{|c|}{0,3395} & \multicolumn{2}{|c|}{0,3495} & \multicolumn{2}{|c|}{0,3649} \\
\hline $\mathrm{N}$ & \multicolumn{2}{|c|}{292} & \multicolumn{2}{|c|}{292} & \multicolumn{2}{|c|}{242} \\
\hline
\end{tabular}

Fonte: Os autores.

Nota: Coeficientes e odd ratios. Erro padrão entre parênteses. * Significante a 0,$10 ; * *$ Significante a 0,$05 ; * *$ Significante a 0,01 .

Como teste de robustez, foi um realizado um teste só com propostas dos ministros com filiação partidária. Os parâmetros foram os mesmos dos modelos 1 e 2 da primeira regressão logística (Tabela 2). Os resultados estão na Tabela A1 (Apêndice).

Os resultados se assemelham aos da Tabela 2. O resultado para a variável de distância ideológica continua significante (embora com uma significância ligeiramente menor) e negativo, indicando que, entre os ministros estritamente partidários, a filiação ao partido do presidente importa para o êxito das propostas no Conselho. Da mesma forma, a variável conflito também obteve resultados significantes e negativos; a variável de capacidade não obteve significância.

É fato que são poucas as propostas de ministros partidários. Isso pode ser reflexo de um excesso de propostas do MDIC, que nos anos analisados sempre esteve dirigido por ministros sem filiação partidária. Entretanto, ao excluir as propostas do MDIC (e de outros ministros sem filiação), os resultados ainda permitem confirmar a Hipótese 1 (distância ideológica).

A não relevância da variável de capacidade é um achado importante. A segunda hipótese previa a possibilidade de que burocracias mais capacitadas pudessem influenciar o êxito dos ministros, o que empiricamente não se veri- 
ficou. Por um lado, não é possível afirmar qual o papel das burocracias sobre o conteúdo das propostas, tendo em vista que não houve uma análise da qualidade das propostas feitas pelos ministros ao Conselho. Por outro lado, as hipóteses levantadas tomavam como base um mecanismo causal bastante complexo: os

Tabela 3 - Regressão ReLogit (VD: Taxa de êxito dos Ministros)

\begin{tabular}{|c|c|c|c|c|}
\hline \multirow[b]{2}{*}{ Variáveis } & \multicolumn{2}{|c|}{ Modelo 1} & \multicolumn{2}{|c|}{ Modelo 2} \\
\hline & Coef & OR & Coef & OR \\
\hline \multirow[t]{2}{*}{ Constante } & $3,603 * * *$ & $36,701 * * *$ & $2,320 * * *$ & $10,179 * * *$ \\
\hline & $(0,427)$ & & $(0,970)$ & \\
\hline \multirow{2}{*}{$\begin{array}{l}\text { Distância } \\
\text { Ideológica }\end{array}$} & $-4,442 * * *$ & $0,012 * * *$ & $-4,620 * * *$ & $0,010 * * *$ \\
\hline & $(1,018)$ & & $(0,986)$ & \\
\hline \multirow[t]{2}{*}{ Capacidade } & $-0,082$ & 0,922 & $-0,052$ & 0,949 \\
\hline & 0,677 & & 0,662 & \\
\hline \multirow[t]{2}{*}{ Oposição } & $-3,153 * * *$ & $0,043 * * *$ & $-3,104 * * *$ & $0,045 * * *$ \\
\hline & $(0,568)$ & & $(0,612)$ & \\
\hline \multirow[t]{2}{*}{ Presidente } & & & 1,315 & 3,723 \\
\hline & & & $(1,067)$ & \\
\hline \multirow[t]{2}{*}{ Ano 1} & & & $-0,385$ & 0,680 \\
\hline & & & $(0,680)$ & \\
\hline \multirow[t]{2}{*}{ Ano 4} & & & 0,512 & 1,668 \\
\hline & & & $(0,707)$ & \\
\hline $\mathrm{N}$ & 292 & & 292 & \\
\hline
\end{tabular}

Fonte: Os autores.

Nota: Coeficientes e odd ratios. Erro padrão entre parênteses. * Significante a 0,10; ** Significante a 0,$05 ; * * *$ Significante a 0,01 .

Gráfico 4 - Relação entre distância ideológica e probabilidade de êxito dos ministros no Conselho de Ministros da Camex (2001-2010)

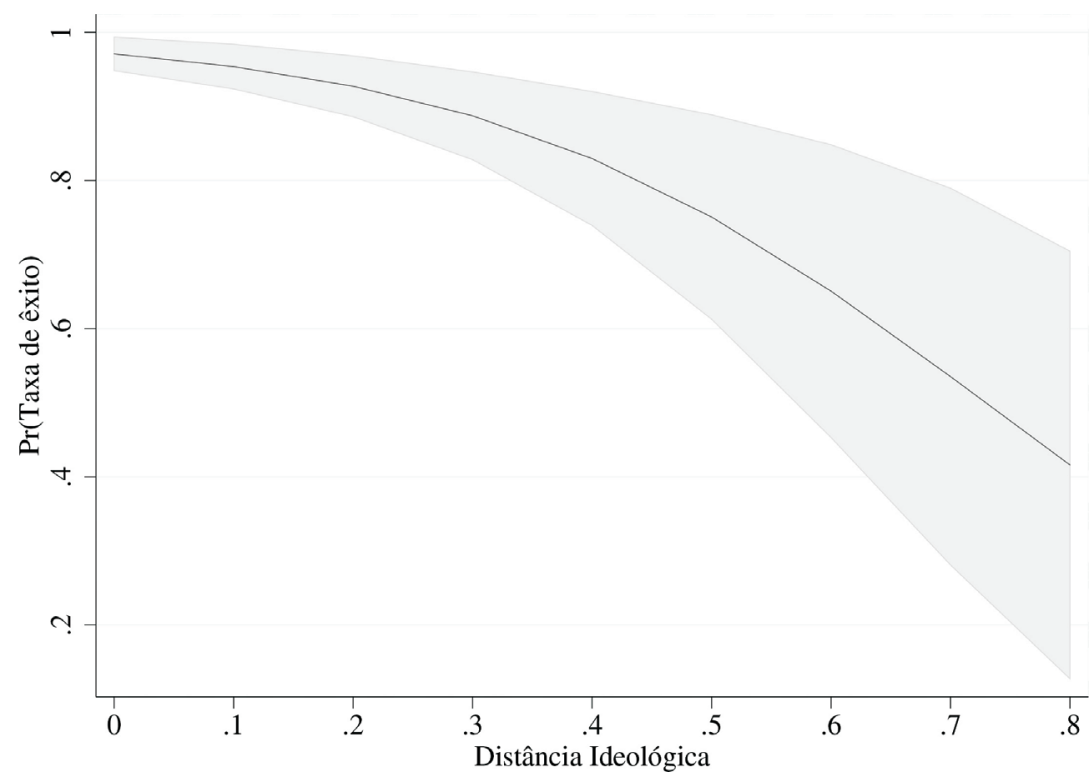

Fonte: Os autores. 
ministros poderiam utilizar as burocracias especializadas para incrementar a qualidade das propostas submetidas ao Conselho, convencendo os demais membros a votar a favor. Como não houve acesso à qualidade das propostas, não é possível afirmar que isso não ocorre. $\mathrm{O}$ fato de a variável capacidade não ter obtido êxito parece indicar que, independentemente do preparo dos servidores dos ministérios, tende a prevalecer a vontade do partido do presidente na Camex. Mesmo sem negar a hipótese do mérito das propostas, a análise empírica confirma que importa mais quem propõe aos ministros do Conselho e quem intervém para mediar, e não necessariamente o que é proposto.

Outro ponto bastante interessante é o baixo desempenho do MAPA, apesar de ser um dos ministérios que mais propõem iniciativas na Camex. Na composição permanente do Conselho de Ministros, trata-se de um dos únicos ministérios que foca políticas de produção de bens de consumo, junto com o próprio MDIC. De acordo com os achados empíricos, pode-se afirmar que os ministros que estiveram à frente do MAPA eram de outro partido que o do presidente. Entre 1999 e 2002, com FHC na presidência, o MAPA esteve com Marcus Vinícius Pratini de Moraes, do PPB; no primeiro mandato de Lula, o MAPA foi dirigido por dois ministros sem filiação partidária, Roberto Rodrigues e Luis Carlos Guedes Pinto; finalmente, no segundo mandato de Lula, por dois ministros filiados ao PMDB, Reinhold Stephanes e Wagner Rossi. Por serem de partidos diferentes do partido do presidente, o fato do MAPA sistematicamente não obter êxito na Camex pode ser entendido pela explicação aqui proposta.

Não obstante, podemos sugerir explicações alternativas. Conforme levantado por Fernandes (2013), a institucionalização da Camex se deu em favor da burocracia do MDIC, que pode ter um viés a favor dos setores industriais. Nesse sentido, é possível que o setor agrícola, embora importante para as exportações, não tenha sido favorecido. Somente uma análise mais aprofundada do conteúdo das propostas poderá confirmar essa tese.

\section{Conclusões}

Os achados empíricos confirmam a hipótese da distância ideológica. Cumpre, porém, fazer algumas ressalvas. Há claramente um viés a favor do êxito. Consequentemente, é possível que ministros que sabem que serão derrotados evitem fazer propostas ao Conselho de Ministros da Camex.

Não obstante, isso não parece afetar o fato de que dificilmente ministros de partidos distintos ao do presidente conseguem aprovar alguma medida. Grande parte das propostas decididas pelo Conselho são pareceres do próprio MDIC. Na prática, medidas que fogem desse padrão são as que interessam ao presente estudo: medidas que os ministros submetem por suas demandas particulares. Nesse ponto, ser do partido presidencial, ainda que na mesma coalizão de governo, é um fator crucial para conseguir aprovar alguma proposta. Entre os ministros da Camex, além de ministros do próprio partido presidencial ou sem filiação partidária, poucos eram de outros partidos. No escopo das propostas analisadas, as iniciativas de ministros de outros partidos foram modestas; em paralelo, se desconsiderarmos as propostas do MDIC e de ministros sem partido, o número de demandas submetidas ao Conselho por parte de ministros filiados a partidos distintos do partido presidencial torna-se significativa para a análise. Da mesma forma, é notória a falta de êxito desses ministros na Camex. Algumas de suas propostas foram aprovadas, mas a grande maioria não.

Uma explicação possível é que a Camex parece agir para coordenar as demandas em matéria de comércio exterior, por um lado, e esvaziar as demandas de outros partidos que não o do presidente, de outro. O interessante no processo decisório do Conselho é o fato de estar limitado ao Poder Executivo. 
Os partidos que compõem a coalizão podem ser mais influentes no Congresso, na aprovação de projetos de lei, em que a proporção de seus deputados pode pesar. No Executivo, a influência é reduzida devido à maneira como os ministros são escolhidos. A distribuição dos ministérios nem sempre é coalescente com os partidos que compõem o gabinete (Amorim Neto 2000; 2006). Dessa forma, partidos da coalizão, mesmo que influentes no Legislativo ou até em seus respectivos ministérios, têm o seu poder de influência limitado em matéria de comércio exterior.

O estudo não se debruçou sobre o conteúdo das propostas. Não obstante, é de se imaginar que as propostas exitosas reflitam preferências do partido do presidente. Quanto mais as propostas se distanciarem dessas preferências, maior deve ser a probabilidade de fracasso. O fato de a variável de capacidade técnica da burocracia não ter sido significante parece reforçar esse argumento. Ministros à frente de burocracias mais preparadas não necessariamente conseguem aprovar suas propostas. Isso não significa que burocracias mais preparadas fazem propostas de melhor qualidade - mais uma vez, somente uma análise mais aprofundada do conteúdo das propostas poderia confirmar tal hipótese.

Por que o presidente sempre consegue obter mais sucesso no Conselho de Ministros? Ou ainda, por que ele ou ela cria entidades de decisão como esta? Os estudos sobre presidencialismo de coalizão indicam que o presidente é responsável eleitoralmente pelo Executivo, o que implica que uma má gestão administrativa poderá ser associada ao presidente e seu partido. Sendo assim, o presidente tem interesse em institucionalizar o processo decisório interno para alguns temas específicos, com o fim de monitorar os parceiros da coalizão e, dessa forma, reduzir o custo eleitoral (Inácio 2006; Lameirão 2011; Batista 2014). Além de institucionalizar, o presidente também pode preencher os quadros do Executivo com membros próximos a ele. O procedimento pelo qual o partido presidencial se insere no governo, de forma exógena ao processo de formação do gabinete, termina por conceder muitos poderes ao presidente e seu partido. Sendo assim, é muito difícil que membros de outros partidos aprovem medidas na Camex, em que, além de tudo, diversos ministros próximos ao presidente fazem parte dos membros.

Tais hipóteses sobre os mecanismos internos de repartição de forças na Camex precisam ser analisadas com maior profundidade. Seria interessante expandir a agenda de estudo para outras entidades com estruturas semelhantes, como outras câmaras ou conselhos do Executivo.

Uma pergunta interessante seria: por que os ministros mais distantes, mesmo sabendo que perderão, ainda fazem propostas? Uma hipótese pode estar ligada à conexão eleitoral, mais especificamente, ao credit claiming (Mayhew 1974): o ministro demonstra ao eleitorado de seu partido que está lutando por suas demandas. Qualquer afirmação nesse sentido demandaria um estudo mais aprofundado e, provavelmente, uma análise quantitativa não seria a mais apropriada, mas uma abordagem qualitativa que focasse as propostas dos ministros que mais perderam no Conselho de Ministros.

É importante ressaltar que, nos últimos anos, a Camex passou por alterações que podem colocar à prova os achados deste trabalho. No segundo mandato de Dilma Rousseff (2015-2016), o senador Armando Monteiro, do PTB-PE, assumiu o MDIC. Foi a primeira vez que esse ministério não esteve com um ministro ideologicamente próximo do partido presidencial. Lembrando da força que o MDIC possuiu no período aqui abordado (2001-2010), seria interessante retomar o estudo para o primeiro mandato de Dilma. 
${ }^{16}$ Convertida na Lei 13.341/2016, alterando a Lei $10.683 / 2003$ sobre a organização da Presidência da República.

17 A partir de agosto de 2017 , o partido retomou o antigo nome, Movimento Democrático Brasileiro (MDB).

18 Doravante Ministério da Indústria, Comércio Exterior e Serviços.

19 Henrique Meirelles deixou o Ministério da Fazenda em abril de 2018, quando se filiou ao MDB; o atual titular da pasta, Eduardo Guardia, não possui filiação partidária.

${ }^{20}$ Depois da saída de Romero Jucá (MDB).

${ }^{21}$ Blairo Maggi era do PR, mas trocou de sigla para poder integrar o governo.

${ }^{22}$ Nova sigla do PTN.
As alterações institucionais feitas pela MP 726/2016 ${ }^{16}$ e pelos decretos 8.807/2016, 8.906/2016 e 9.029/2017, com a presidência de Michel Temer $\left(\mathrm{PMDB}^{17}\right)$, produziram alterações que também podem colocar nossos achados empíricos em cheque. Primeiro, a Camex deixou de ser sediada no MDIC e passou para o MRE, ou seja, passou a fazer parte da própria Presidência. Segundo, o Ministro-Chefe da Casa Civil, que havia sido excluído da Camex pelo decreto 8.807/2016, voltou à estrutura pelo decreto $8.906 / 2016$, passando a presidir o Conselho. Terceiro, o MDA (unido ao Ministério do Desenvolvimento Social) deixou de integrar o Conselho. Dois novos ministros passaram a integrá-lo: o Ministro dos Transportes, Portos e Aviação Civil (MT) e o Ministro Chefe da Secretaria-Geral da Presidência da República (SGPR). Assim, na nova configuração estão o Ministro-Chefe da Casa Civil, MRE, MF, MAPA, MDIC ${ }^{18}$, MP, MT e SGPR -8 ministros, um a mais que no período 2001-2010.

Na composição do gabinete (04/2017), a Casa Civil estava com o PMDB, o $\mathrm{MF}^{19}$ e o MP ${ }^{20}$ estavam com ministros sem filiação partidária. O MRE estava com o PSDB (Aloisio Nunes); o MDIC, com o PRB; o MAPA, com o PP21; o MT estava com o PR e passou a ter um ministro sem filiação partidária; a SGPR estava com o PMDB e mudou para o $\mathrm{PODE}^{22}$.

Portanto, além das mudanças institucionais, temos com Temer a maior fragmentação partidária que já passou pelo Conselho. Tal estrutura pode por à prova a hipótese da distância ideológica na Camex. Finalmente, foi implementada uma reivindicação antiga (Decreto 3.756/2001) de setores organizados da sociedade civil, principalmente a Confederação Nacional da Indústria (CNI 2014), que demandavam que a Camex voltasse à Presidência, com a Casa Civil à sua frente. Interessante observar também que tal estrutura foi consolidada pelo Decreto 8.906/2016, embora não seja possível afirmar que a responsável pela mudança tenha sido a pressão do setor industrial.

Para os achados deste estudo, talvez a Camex reduza o número de atores envolvidos na negociação - mais ainda se os interesses dos setores estiverem alinhados com os do presidente. Em todo caso, é necessário retomar os resultados para além do período estudado.

ILeonardo Gill Correia Santos (gillcorreia.santos@gmail.com) é Mestre em Ciência Política e Doutorando em Ciência Política pela Universidade Federal de Pernambuco (UFPE). Vínculo institucional: Programa de Pós-Graduação em Ciência Política da Universidade Federal de Pernambuco, UFPE, Recife, PE, Brasil.

IIAndrea Quirino Steiner (ecodea@gmail.com) é Doutora em Ciência Política pela Universidade Federal de Pernambuco (UFPE) e Professora Adjunta do Departamento de Ciência Política da mesma universidade. Vínculo institucional: Programa de Pós-Graduação em Ciência Política da Universidade Federal de Pernambuco, UFPE, Recife, PE, Brasil.

\section{Referências}

Amorim Neto, O., 2000. Gabinetes presidenciais, ciclos eleitorais e disciplina legislativa no Brasil. Dados, 43(3), pp.479-519. DOI: $10.1590 / \mathrm{S} 0011-52582000000300003$

Amorim Neto, O., 2002. Presidential Cabinets, Electoral Cycles, and Coalition Discipline in Brazil. In S. Morgenstern \& B. Nacif, eds. Legislative Politics in Latin America. New York: Cambridge University Press.

Amorim Neto, O., 2006. Presidencialismo e governabilidade nas américas. Rio de Janeiro: Editora FGV.

Batista, M., 2013. O poder no Executivo: uma análise do papel da presidência e dos ministérios no presidencialismo de coalizão brasileiro (1995-2010). Opinião Pública, 9(2), pp.449-473. DOI: 10.1590/S0104-62762013000200009

Batista, M., 2014. O Mistério dos ministérios: a governança da coalizão no presidencialismo brasileiro. Tese de Doutorado. Recife: Universidade Federal de Pernambuco.

Bersch, K.; Praça, S. \& Taylor, M., 2013. State Capacity and Political Autonomy Dataset. The State Capacity Project. Disponível em https://sites.google.com/site/thestatecapacityproject/data. Acesso em 22 abr. 2016.

Bersch, K.; Praça, S. \& Taylor, M., 2016. State Capacity, Bureaucratic Politicization, and Corruption in the Brazilian State. Governance, 30(1), pp.105-124. DOI: 10.1111/gove.12196

Cheibub, J., 2007. Presidentialism, Parliamentarism, and Democracy. Cambridge: Cambridge University Press. 
Cheibub, J.; Przeworski, A. \& Saiegh, S., 2002. Governos de coalizão nas democracias presidencialistas e parlamentaristas. Dados, 45(2), pp.187-218. DOI: 10.1590/S0011-52582002000200001

Fernandes, I., 2013. A Construção Institucional da Política Comercial Brasileira: a Câmara de Comércio Exterior (Camex) no Governo Cardoso. Revista de Sociologia e Política, 21(45), pp.123-148. DOI: 10.1590/S0104-44782013000100010

Figueiredo, A., 2007. Government Coalitions in Brazilian Democracy. Brazilian Political Science Review, vol 1(2), pp.182-216.

Figueiredo, A. \& Limongi, F., 2001. Executivo e Legislativo na nova ordem constitucional. Rio de Janeiro: Editora FGV.

Figueiredo, A. \& Limongi, F., 2008. Política orçamentária no presidencialismo de coalizão. Rio de Janeiro: Editora FGV.

Inácio, M., 2006. Entre Presidir e Coordenar: Presidência e Gabinetes Multipartidários no Brasil. In 3o Encontro Latino-Americano de Ciência Política. Campinas.

King, G. \& Zeng, L., 2001. Logistic Regression in Rare Events Data. Political Analysis, 9(2), pp.137-163 Disponível em: http://gking.harvard.edu/category/research-interests/methods/rare-events. Acesso em 22 abr. 2019.

Lameirão, C., 2011. A Casa Civil como instituição do Executivo Federal. Desigualdade \& Diversidade (Dossiê Especial, Segundo Semestre), pp.143-184.

Laver, M. \& Shepsle, K., 1990. Coalitions and Cabinet Government. The American Political Science Review, 84(3), pp.873-890. DOI: 10.2307/1962770

Laver, M. \& Shepsle, K., 1994. Cabinet Ministers and Parliamentary Government. Cambridge: Cambridge University Press.

Laver, M. \& Shepsle, K., 1996. Making and Breaking Governments: Government Formation in Parliamentary Democracies. New York: Cambridge University Press.

Martin, L. \& Vanberg, G., 2011. Parliaments and Coalitions: The Role of Legislative Institutions in Multiparty Governance. Oxford: Oxford University Press.

Martin, L. \& Vanberg, G., 2013. Multiparty Government, Fiscal Institutions, and Public Spending. The Journal of Politics, 75(4), pp.953-967. DOI: 10.2139/ssrn.2020533

Martin, L. \& Vanberg, G., 2014. Parties and Policymaking in Multiparty Governments: The Legislative Median, Ministerial Autonomy, and the Coalition Compromise. The American Journal of Political Science, 58(4), pp.979-996. DOI: 10.1111/ajps.12099

Mayhew. D., 1974. Congress: The Electoral Connection. New Haven: Yale University Press.

Müller, W.; Bergman, T. \& Strøm, K., 2008. Coalition Theory and Cabinet Governance: An Introduction. In K. Strøm; W. Müller \& T. Bergman, eds. Cabinets and Coalition Bargaining: The Democratic Life Cycle in Western Europe. Oxford: Oxford University Press.

Power, T. \& Zucco, C., 2011a. Brazilian Legislative Surveys (1990-2013). Harvard Dataverse, 5. DOI: 10.7910/DVN/T2PW7F Disponível em https://dataverse.harvard.edu/dataset.xhtml?persistentId=hdl:1902.1/14970. Acesso em 22 abr. 2019.

Power, T. \& Zucco, C., 2011b. O Congresso por ele mesmo: autopercepções da classe política brasileira. Belo Horizonte: Editora UFMG.

Riker, W., 1962. The Theory of Political Coalitions. New Haven: Yale University Press.

Rubinstein, A., 1982. Perfect Equilibrium in a Bargaining Model. Econometrica, 50(1), pp.97-109. DOI: 10.2307/1912531

Rudalevige, A., 2002. Managing the President's Program: Presidential Leadership and Legislative Policy Formulation. New Jersey: Princeton University Press.

Strøm, K.; Müller, W. \& Bergman, T., 2003. Delegation and Accountability in Parliamentary Democracies. Oxford: Oxford University Press.

Zucco, C. \& Lauderdale, B., 2011. Distinguishing Between Influences on Brazilian Legislative Behavior. Legislative Studies Quaterly, 36(3), pp.363-396. DOI: 10.1111/j.1939-9162.2011.00019.x

\section{Outras fontes}

Brasil, 1995. Decreto no . 1.386. De 6 de fevereiro de 1995. Cria a Câmara de Comércio Exterior. Do Conselho de Governo, e dá outras providências.

Brasil, 1998. Lei nº 9.649. De 27 de maio de 1998. Dispõe sobre a organização da Presidência da República e dos Ministérios, e dá outras providências.

Brasil, 2001. Decreto $n^{\circ}$. 3.756. De 21 de fevereiro de 2001. Dispõe sobre a Camex - Câmara de Comércio Exterior e dá outras providências.

Brasil, 2001a. Decreto $n^{o}$. 3.981. De 24 de outubro de 2001. Dispõe sobre a Camex - Câmara de Comércio Exterior. Do Conselho de Governo, e dá outras providências.

Brasil, 2003. Decreto $n^{o}$. 4.732. De 10 de junho de 2003. Dispõe sobre a Câmara de Comércio Exterior - Camex. Do Conselho do Governo.

Brasil, 2011. Lei $n^{o}$. 12.527. De 18 de novembro de 2011. Regula o acesso a informações previsto no inciso XXXIII do art. 5ㅜㅡ, no inciso II do $\S 3^{\circ}$ do art. 37 e no $\S 2^{\circ}$ do art. 216 da Constituição Federal; altera a Lei n ${ }^{\circ}$. 8.112. De 11 de dezembro de 1990; revoga a Lei $n^{\circ}$. 11.111. De 5 de maio de 2005, e dispositivos da Lei ${ }^{\circ}$. 8.159. De 8 de janeiro de 1991; e dá outras providências.

Brasil, 2016. Medida Provisória nº. 726. De 12 de maio de 2016. Altera e revoga dispositivos da Lei nº. 10.683. De 28 de maio de 2003, que dispõe sobre a organização da Presidência da República e dos Ministérios. 
Brasil, 2016a. Decreto ${ }^{\circ}$. 8.807. De 12 de julho de 2016. Altera o Decreto no. 4.732. De 10 de junho de 2003, que dispõe sobre a Câmara de Comércio Exterior - Camex, e o Decreto no. 4.993. De 18 de fevereiro de 2004, e dá outras providências.

Brasil, 2016b. Lei $n^{\circ}$. 13.341. De 29 de setembro de 2016. Altera as Leis $n^{\circ}$. 10.683. De 28 de maio de 2003, que dispõe sobre a organização da Presidência da República e dos Ministérios, e 11.890. De 24 de dezembro de 2008, e revoga a Medida Provisória nº 717 . De 16 de março de 2016.

Brasil, 2016c. Decreto $n^{o}$. 8.906. De 21 de novembro de 2016. Altera o Decreto no 4.732. De 10 de junho de 2003, quanto à Presidência da Câmara de Comércio Exterior - Camex.

Brasil, 2017. Decreto $n^{\circ}$. 9.029. De 10 de abril de 2017. Altera o Decreto ${ }^{\circ}$ 4.732. De 10 de junho de 2003, que dispõe sobre a Câmara de Comércio Exterior - Camex. Da Presidência da República, o Decreto n ${ }^{\circ} 4.993$. De 18 de fevereiro de 2004, que cria o Comitê de Financiamento e Garantia das Exportações - COFIG, o Decreto nº 9.004. De 13 de março de 2017, que transfere a Secretaria de Aquicultura e Pesca do Ministério da Agricultura, Pecuária e Abastecimento e a Secretaria Especial da Micro e Pequena Empresa da Secretaria de Governo da Presidência da República para o Ministério da Indústria, Comércio Exterior e Serviços, e o Decreto n ${ }^{\circ}$ 715. De 29 de dezembro de 1992, que delega aos Ministros de Estado do Trabalho e da Indústria, Comércio Exterior e Serviços competência para aprovar os orçamentos das entidades que menciona.

Camex. Câmara de Comércio Exterior, 2005. Resolução $n^{o}$. 11. De 25 de abril de 2005. Aprova, na forma do Anexo, o Regimento Interno da Camex.

Camex. Câmara de Comércio Exterior, 2001. Resolução nº 12. De 10 de maio de 2001. Adota o Regimento Interno da Camex. CNI. Confederação Nacional da Indústria, 2014. Comércio exterior: propostas de reformas institucionais. Brasília: CNI.

\section{Decision-Making Process in the Executive: an Analysis of CAMEX in Coalitional Presidentialism}

ABSTRACT Introduction: Who wins more in foreign trade policy? This paper analyses the decision-making process of the Chamber of Foreign Trade (Camex), within Brazilian coalitional presidentialism. Ministers from different parties with divergent preferences must decide on several proposals of foreign trade policy. Our central hypothesis was that the larger the ideological distance between one minister's party and the president's party, the less the success in Camex. Materials and Methods: Using content analysis to examine Camex's Council of Ministers meeting records between 2001 and 2010, we collected 292 proposals of trade defense and tariff modifications submitted by ministers to Camex. We then used data on ministerial partisanship and ideological position from parties in Congress. We then employed logistic regression and rare event logit (ReLogit) techniques to verify whether ideological distance matters for ministerial success. Results: Despite some statistical caveats, our results confirm the central hypothesis, with a negative and significant impact of the ideological distance on the success of ministers. Regression models have to account for punctual oppositions of Camex's members over some ministers' proposals. Discussion: Therefore, Camex can be considered an institutionalized body of control of the president over the cabinet, in addition to the further presidential accountability tools.

Keywords: Coalitional Presidentialism; Political Institutions; Executive Branch; Camex; Foreign Trade.

This is an Open Access article distributed under the terms of the Creative Commons Attribution Non-Commercial License which permits unrestricted non-commercial use, distribution, and reproduction in any medium provided the original work is properly cited. 


\section{Apêndice}

Tabela A1 - Regressão Logística (Taxa de êxito dos Ministros com Filiação Partidária)

\begin{tabular}{|c|c|c|c|c|}
\hline \multirow[b]{2}{*}{ Variáveis } & \multicolumn{2}{|c|}{ Modelo 1} & \multicolumn{2}{|c|}{ Modelo 2} \\
\hline & Coef & OR & Coef & OR \\
\hline \multirow[t]{2}{*}{ Constante } & $2,368 * * *$ & $10,680 * * *$ & 1,611 & 5,009 \\
\hline & $(0,801)$ & $(8,555)$ & $(1,342)$ & $(6,723)$ \\
\hline \multirow{2}{*}{$\begin{array}{l}\text { Distância } \\
\text { Ideológica }\end{array}$} & $-2,838 * *$ & $0,059 * *$ & $-3,404 * *$ & $0,033 * *$ \\
\hline & $(1,215)$ & $(0,071)$ & $(1,656)$ & $(0.055)$ \\
\hline \multirow[t]{2}{*}{ Capacidade } & 0.018 & 1,018 & 0,137 & 1,147 \\
\hline & $(0,516)$ & $(0,526)$ & $(0.559)$ & $(0,641)$ \\
\hline \multirow[t]{2}{*}{ Oposição } & $-4,022 * * *$ & $0,018 * * *$ & $-4,021 * *$ & $0,018 * *$ \\
\hline & $(1,375)$ & $(0,025)$ & $(1,733)$ & $(0,031)$ \\
\hline \multirow[t]{2}{*}{ Presidente } & & & 1,106 & 3,021 \\
\hline & & & $(1,600)$ & $(4,835)$ \\
\hline \multirow[t]{2}{*}{ Ano 1} & & & $-0,454$ & 0,635 \\
\hline & & & $(1,498)$ & $(0,952)$ \\
\hline \multirow[t]{2}{*}{ Ano 4} & & & 0,131 & 1,141 \\
\hline & & & $(0,860)$ & $(6,723)$ \\
\hline Log Likelihood & \multicolumn{2}{|c|}{$-28,038438$} & \multicolumn{2}{|c|}{$-27,757818$} \\
\hline LR chi ${ }^{2}$ & \multicolumn{2}{|c|}{18,02} & \multicolumn{2}{|c|}{18,58} \\
\hline Prob $>$ chi $^{2}$ & \multicolumn{2}{|c|}{0,0004} & \multicolumn{2}{|c|}{0,0049} \\
\hline Pseudo $\mathrm{R}^{2}$ & \multicolumn{2}{|c|}{0,2432} & \multicolumn{2}{|c|}{0.2508} \\
\hline $\mathrm{N}$ & \multicolumn{2}{|c|}{56} & \multicolumn{2}{|c|}{56} \\
\hline
\end{tabular}

Fonte: Os autores.

Nota: Coeficientes e odd ratios. Erro padrão entre parênteses. * Significante a 0,10; ** Significante a 0,05; *** Significante a 0,01 . 
Quadro 1A - Glossário de Siglas

\begin{tabular}{|c|c|}
\hline Sigla & Nome \\
\hline$B N D E S$ & Banco Nacional de Desenvolvimento Econômico e Social \\
\hline Camex & Câmara de Comércio Exterior \\
\hline$C C$ & Ministro-Chefe da Casa Civil \\
\hline CNI & Confederação Nacional da Indústria \\
\hline Gecex & Comitê Executivo de Gestão \\
\hline$G T$ & Grupo de Trabalho da SE/Camex \\
\hline$L A I$ & Lei de Acesso à Informação 12.527/2011 \\
\hline Letec & Lista de Exceções à Tarifa Externa Comum do Mercosul \\
\hline$M A P A$ & Ministério da Agricultura, Pecuária e Abastecimento \\
\hline$M D$ & Ministério da Defesa \\
\hline$M D A$ & Ministério do Desenvolvimento Agrário \\
\hline$M D I C$ & Ministério do Desenvolvimento, Indústria e Comércio Exterior \\
\hline$M F$ & Ministério da Fazenda \\
\hline$M J$ & Ministério da Justiça \\
\hline$M M E$ & Ministério de Minas e Energia \\
\hline$M P$ & Ministério do Planejamento, Orçamento e Gestão \\
\hline$M P A$ & Ministério de Pesca e Aquicultura \\
\hline$M R E$ & Ministério de Relações Exteriores \\
\hline$M S$ & Ministério da Saúde \\
\hline$M T$ & Ministro dos Transportes, Portos e Aviação Civil \\
\hline$P M D B$ & Partido do Movimento Democrático Brasileiro \\
\hline$P O D E$ & Podemos (ex-Partido Trabalhista Nacional) \\
\hline$P P B$ & Partido Progressista Brasileiro \\
\hline$P R$ & Partido Republicano \\
\hline$P R B$ & Partido Republicano Brasileiro \\
\hline$P S D B$ & Partido da Social Democracia Brasileira \\
\hline$P T B$ & Partido Trabalhista Brasileiro \\
\hline SE/Camex & Secretaria Executiva da Camex \\
\hline$S G P R$ & Ministro Chefe da Secretaria-Geral da Presidência da República \\
\hline
\end{tabular}

Nota: No texto, as siglas referentes aos ministérios também se referem aos ministros das pastas, a depender do contexto. 